CHAPTER 16

\title{
Eating Disorders: Traumatic Context and Interventions
}

\author{
Diedra L. Clay
}

\begin{abstract}
Historically, women's eating disorders have been denominated with such terms as 'chlorosis', 'neurasthenia' and 'hysteria'. Since the 1970s an increase in eating disorders have been noticed, possibly correlated with the general phenomenon of cultural gender role change, posited as attributable to the confusion between the terms 'sex' and 'gender'. The biological term 'sex' works for both female and male, while the socially given term 'gender' is either masculine or feminine. This traumatic bifurcation implicitly involves a cultural dualism. The theoretical consideration of eating disorders has been likened to the crystallisation of culture, with three cultural axes: the dualist axis, control axis, and gender/power axis. Dualism can be thought of as a denied dependency on a subordinated or traumatised other. Within this frame, human existence bifurcates into two territories or substances: that of the body and materiality, as contrasting that of the mental and spiritual. The body must be escaped from a prison and an enemy with which to struggle. In this battle, thinness represents a triumph of the will over the body. The control axis is informed by the experience of one's hungers as being out of control. One's ability to ignore hunger and pain evidences one's control over one's own body, often the only control one experiences. The gender/power axis is informed by the experience of one's 'female' portions of one's body, usually at menarche, as a disgusting appropriation of one's body by fat. These symptoms emerge as an unconscious protest at the limitations of the traditional female role. Successful interventions with eating disorders take these intersecting factors into account. This chapter will expose the range of current treatment interventions in consideration of the traumatic context.
\end{abstract}

\section{Keywords}

traumatic cultural context - interventions - gender role - dualism - female - eating disorders 
Historians long ago began to write the history of the body. They have studied the body in the field of historical demography or pathology; they have considered it as the seat of needs and appetites, as the locus of physiological processes and metabolisms, as a target for the attacks of germs or viruses; they have shown to what extent historical processes were involved in what might seem to be the purely biological 'events' such as the circulation of bacilli, or the extension of the lifespan. But the body is also directly involved in a political field; power relations have an immediate hold upon it; they invest it, mark it, train it, torture it, force it to carry out tasks, to perform ceremonies, to emit signs. ${ }^{1}$

The death of the singer Karen Carpenter in 1983 served to focus mass media attention, and therefore mass population attention, on the phenomenon of clinical eating disorders in general and anorexia nervosa in particular. ${ }^{2} \mathrm{Ms}$. Carpenter's highly popular success in her singing career, combined with her extreme preoccupation with her weight, struck a profound and dramatic cultural chord. The extreme dissonance between her rapid stardom and her equally rapid and abrupt death from anorexia nervosa helped to convince people of the extreme seriousness of clinical eating disorders. For some, her death was the very first instance of an eating disorder entering into the popular cultural awareness. Many theories emerged regarding the circumstances behind the development of her clinical eating disorder. Soon after, medical and health care professionals began to recognise, regularly diagnose and treat clinical eating disorders in both in- and out-patient treatment centres. Eating disorders became recognisable in popular press and general cultural knowledge.

As a viewable cultural phenomenon, a close examination of clinical eating disorders must necessarily connect with a careful and thorough exploration of the categories of gender and embodiment. Most people diagnosed with, and hospitalised for, anorexia nervosa are female. ${ }^{3}$ An important descriptive criterion for the diagnosis of anorexia nervosa is the presence of significant

1 Michel Foucault, Discipline and Punish: The Birth of the Prison (New York: Vintage/Random House, 1979), 25 .

2 Joel Samberg, 'Remembering Karen Carpenter, 30 Years Later', NPR Music (website), 4 February 2013, Viewed on 9 April 2015, http://www.npr.org/2013/o2/04/171080334/rememberingkaren-carpenter-3o-years-later.

3 Susan Faludi, Backlash: The Undeclared War Against American Women (New York: Doubleday, 1991), 202. 
negative disturbances in an individual's body perception. ${ }^{4}$ Thus in light of the current incidence of clinical eating disorder cases a consideration of the interconnecting aspects of gender and embodiment proves essential.

In this chapter, the term gender is used broadly to outline an analytic category for an examination that traditionally refers to the study of sex, sex roles, gender, gender roles, gender bias, gender role identity, gender expectations, gender role attitudes, sexism, femininity, masculinity, androcentrism and language use. ${ }^{5}$ Similarly, the term embodiment is used as an analytic category for examination to refer to body image, body image expectations, biological sex, one's experience of being in one's body, and one's relationship to one's body. ${ }^{6}$

The literature in the respective areas of gender, embodiment and clinical eating disorders includes hundreds of psychological analyses, experimental studies, meta-studies, single case studies, treatment recommendations and theoretical formulations. Much of the clinical literature on eating disorders attempts to link eating disorders with one or another specific pathogenic condition, such as depressive, perceptual, hypothalamic or affective geneses. Psychologists, analysts, therapists, physicians and medical providers historically have provided a plethora of rationales for the origin, development, and treatment of clinical eating disorders. ${ }^{7}$ Nevertheless, both anorexia nervosa and bulimia nervosa appear in ever-increasingly diverse populations of women, in diverse cultures, which drastically reduces the possibility of describing a single distinctive clinical profile for either. ${ }^{8}$ A polyvocal search must therefore be embraced, in order to study the phenomena. Our examination will review the historical, cultural, and religious underpinnings of this disorder.

Traditionally, women's health disorders have been denominated in a wide variety of ways. Terms used have included such descriptions as 'young women's disease', 'chlorosis', 'neurasthenia', and 'hysteria.' For example, the Hippocratic texts

4 Attia, Evelyn; Becker, Anne E.; Bryant-Waugh, Rachel; Hoek, Hans W.; Kreipe, Richard E.; Marcus, Marsha D.; Mitchell, James E.; Striegel, Ruth H.; Walsh, B. Timothy; Wilson, G. Terence; Wolfe, Barbara E.; Wonderlich, Stephen./Feeding and Eating Disorders in DSM-5. In: American Journal of Psychiatry, 170.11 (2013) 1237-1239.

5 Mary Gergen and Sara Davis, Towards a New Psychology of Gender (New York: Routledge, 1997), 39 .

6 Ibid., 40.

7 Ibid., 42.

8 Susan Bordo, Unbearable Weight (Berkeley, CA: University of California Press, 1993), 139-164. 
of fourth century Greece described a 'young women's disease' that began just at menarche and was graphically characterised by amenorrhea, wasting away, great hunger, vomiting, depression, suicidal ideation, anxiety, aches and pains and breathing difficulties. ${ }^{9}$ Other historical authors described a disorder known as 'chlorosis', wherein young girls exhibited symptoms of amenorrhea, appetite disturbance, bingeing and vomiting, depression, anxiety, headache, slenderness, breathing difficulties and insomnia, as well as a disturbed body image. ${ }^{10}$

Savage portrayed a typical case of 'neurasthenia' as one in which

a woman, generally single ... becomes bed-ridden, often refuses her food, or is capricious about it, taking strange things at odd times, or pretending to starve. ... The body wastes, and the face has the thin, anxious look not unlike that represented by Rossetti in many of his pictures of women. ${ }^{11}$

Breuer and Freud described a malady that they called 'hysteria', so named because it was believed to originate in the patient's uterus. ${ }^{12}$ It served as 'a dramatic medical metaphor for everything that men found mysterious or unmanageable in the opposite sex.13 Chronic vomiting, depression, anxiety, headache, difficulty breathing, insomnia, menstrual irregularity and anorexia characterised this disorder. As can be seen historically, the above descriptions of the disorders have many similar qualities to the common contemporary understanding of clinical eating disorders.

In current psychological permutations, the descriptive criteria for anorexia nervosa consist of the following characteristics: the patient (a) manifests a refusal to maintain a minimally normal body weight, (b) becomes intensely afraid of gaining weight, and (c) exhibits significant disturbance in the perception of the shape or size of the body. Anorectics are also amenorrheic, primarily due to abnormally low oestrogen levels on account of the diminished pituitary secretion of follicle-stimulating hormones and luteinising hormones. ${ }^{14}$

9 Ibid., $1-44$.

10 Mary R. Lefkowitz and Maureen B. Fant, Women's Life in Greece and Rome, 1-294 (Baltimore: Johns Hopkins University Press, 1982).

11 George H. Savage, Insanity and Allied Neurosis (Philadelphia: Henry C. Lea, 1884), 9o.

12 Joseph Breuer and Sigmund Freud, Studies on Hysteria (New York: Penguin Press, 1982), 1-170.

13 Mark S. Micale, 'Hysteria and Historiography: A Review of Past and Present Writings', History of Science 27 (1989): 319.

14 Attia, Evelyn; Becker, Anne E.; Bryant-Waugh, Rachel; Hoek, Hans W.; Kreipe, Richard E.; Marcus, Marsha D.; Mitchell, James E.; Striegel, Ruth H.; Walsh, B. Timothy; Wilson, G. Terence; Wolfe, Barbara E.; Wonderlich, Stephen./Feeding and Eating Disorders in DSM-5. In: American Journal of Psychiatry, 170.11 (2013) 1237-1239. 
Anorectics can be described as either the restricting type or the bingeeating/purging type. The restricting type or anorectic typically restricts food intake through fasting or dieting, or by excessive exercise. The binge-eating/ purging type most often indulges in regular binge eating and then purges through self-induced vomiting or through the misuse of laxatives, diuretics or enemas. ${ }^{15}$

Bulimics, on the other hand, have:

1. Recurrent episodes of binge eating. An episode of binge eating requires both: (a) eating, in a discreet period such as within any two-hour period, an amount of food definitely larger than most people would eat during a similar period and under similar circumstances; and (b) experiencing the sense of a lack of control over the eating during the episode, such as feeling the inability to stop eating or to control what or how much is eaten.

2. Recurrent inappropriate compensatory behaviour in order to prevent weight gain, such as (a) self-induced vomiting; (b) misuse of laxatives, diuretics, enemas or other medications; (c) fasting or (d) excessive exercise.

3. Both binge eating and inappropriate compensatory behaviours, on average, at least twice every week for at least three months.

4. Self-evaluation unduly influenced by body shape or weight.

5. The disturbance not occurring exclusively during episodes of anorexia nervosa.

One may specify the bulimia type as either purging or non-purging. For purging types, during the current episode of bulimia nervosa, the person has regularly engaged in self-induced vomiting or the misuse of laxatives, diuretics or enemas. For non-purging types, during the current episode of bulimia nervosa, the person has used other inappropriate compensatory behaviours such as fasting or excessive exercise. The non-purging type person does not regularly engage in self-induced vomiting or misuse of laxatives, diuretics or enemas. ${ }^{16}$

The meaning of gender and embodiment in the experience of a woman with a clinical eating disorder is characterised by a number of events that cause the patient to spiral downward into hopelessness, depression and

15 American Psychiatric Association, op. cit.
16 American Psychiatric Association, op. cit. 
negative self-esteem. The literature consistently addresses the importance of others' perceptions, specifically a negative comment from an important and significant person in authority provoking and continuing to reinforce anorexic-type behaviour. ${ }^{17}$ The provocation results, in part, from the authoritative significant persons' critical attitudes toward the age, gender, and body of the person addressed, as well as their own perceptions of the ideal feminine body and their own age and gender. ${ }^{18}$ The clinical eating disordered individual, in many cases, develops the disorder as an attempt to 'gain control' over their body to counter the significant authority figure's critical and negative evaluation of her body. In turn, after triggering the disordered eating behaviour, negative self-esteem related to body image can directly influence the development, persistence, and perpetuation of the clinical eating disorder. ${ }^{19}$

Apart from a significant person's pejorative appraisal, the media - such as television, advertising, social networking, and fashion magazines - can directly and negatively influence perceptions of the ideal feminine body. ${ }^{20}$ The media often present the ideal woman as physically flawless. ${ }^{21}$ Television and media in print often drastically modify women's bodies to show an idealised version rather than the actual picture with accurate proportions of the women photographed. Women exposed to such excessive, idealised and often impossible to achieve societal demands of physical perfection may succumb to these ideals and measure their own success, self-worth, and self-esteem by externally comparing their own bodies with unrealistic internalised images. In adopting cultural expectations - in taking a critical perspective and treating the feminine body as an object - women with a clinical eating disorder can be 'caught up in a power situation of which they are themselves the bearers' 22 and actively produce the feminine body as an object to herself. ${ }^{23}$ The anorexic woman's perceptions of the feminine body may then intertwine with her perceptions of the feminine role as negative, limiting and devalued in society.

\footnotetext{
17 Hilde Bruch, Eating Disorders: Obesity, Anorexia Nervosa, and the Person Within (New York: Basic Books 1973), go.

18 Ibid, 102.

19 Rita Snyder and Lynn Hasbrouck, 'Feminist Identity, Gender Traits, and Symptoms of Disturbed Eating among College Women', Psychology of Women Quarterly 20.4 (1996): 593-598.

$20 \quad$ Ibid., $593-598$.

21 Faludi, Backlash, 203.

22 Foucault, Discipline and Punish, 25.

23 Faludi, Backlash, 203.
} 
Changes in the incidences of clinical eating disorders over the few last decades have increased astonishingly. In the 1970s, when Bruch published her pioneering works on eating disorders, she could still state that anorexia was very 'rare indeed'. ${ }^{24}$ Subsequently, however, the statistics for clinical eating disorder indicators grew by leaps and bounds. For example, almost half of the women in the United States are on a diet on any given day and 8o percent of women state their dissatisfaction with their appearance. ${ }^{25}$ Epidemiological statistics show that eating disorders affect five to ten million adolescent girls and women as opposed to one million for boys and men. ${ }^{26}$ Far from rare, eating disorders are now indeed epidemic.

Contemporarily, clinical eating disorders have acquired a cultural legitimacy as a significant set of psychological disorders in their own right. As Perlick and Silverstein hinted, the historical syndromes called young women's disorder, chlorosis, neurasthenia and hysteria (outlined in the History section above) correlate with a general phenomenon of cultural gender role change. ${ }^{27}$ Currently, a cultural shift has occurred in the expectations of women's behaviour. According to Perlick and Silverstein, larger populations of women graduate from college than in previous generations, and this newer population may be highly influenced by their perceptions of their mothers' limited lives and restricted opportunities. ${ }^{28}$

Feminist scholars such as Plumwood hold that central to the exploration of clinical eating disorders is the confusion over the categories of 'sex' and 'gender'. ${ }^{29}$ Much of the Western cultural tradition has variously blurred

24 Hilde Bruch, The Golden Cage: The Enigma of Anorexia Nervosa (New York: Vintage, 1979), 1-174.

25 Linda Smolak, Michael P. Levine, and Ruth Striegel-Moore, The Developmental Psychopathology of Eating Disorders: Implications for Research, Prevention, and Treatment, 1-464 (Mahway, NJ: Lawrence Erlbaum Associates, 1996).

26 Janis H. Crowther, Eve M. Wolf and Nancy E. Sherwood, 'Epidemiology of Bulimia Nervosa', The Etiology of Bulimia Nervosa: The Individual and Familial Context, Eds. Janis H. Crowther and Daniel L Tenenbaum, 4-16 (Washington, DC: Hemisphere Publishing Corporation, 1992).

27 Deborah Perlick and Brett Silverstein, 'Faces of Female Discontent: Depression, Disordered Eating, and Changing Gender Roles', in Feminist Perspectives on Eating Disorders, Eds. Patricia Fallon, Melanie A. Katzman and Susan C. Wooley, 77-93 (New York: Guilford Press, 1994).

28 Ibid., 77-93.

29 Val Plumwood, 'Do We Need a Sex Gender Distinction?' Radical Philosophy 51 (1989): 2-11. 
and emphasised the difference between sex and gender. Stoller defined the distinction:

With a few exceptions, there are two sexes, male and female. To determine sex one must assay the following conditions - chromosomes, external genitalia, internal genitalia, gonads, hormonal states and secondary sex characteristics. One's sex, then, is determined by an algebraic sum of all these qualities, and as is obvious, most people fall under one of the two separate bell curves, the one of which is called 'male', the other 'female'.

Gender is a term that has psychological and cultural rather than biological connotations, if the proper terms for sex are 'male' and 'female', the corresponding terms for gender are 'masculine' and 'feminine', these latter being quite independent of (biological) sex. Gender is the amount of masculinity and femininity found in a person, and obviously, while there are mixtures of both in many humans, the normal male has a preponderance of masculinity and the normal female a preponderance of femininity. ${ }^{30}$

From this perspective, sex, or that which is biological, is seen to be normally male or female, while gender, or that which is socially given, is masculine or feminine. This distinction is usually blurred into uniform terms such as 'sexual differences', meaning that which has to do with a particular person inclusive of sex and gender. Consider the use of the word mother to indicate one who both bears and nurtures a child, yet giving birth (biological) and raising a child (sociological) are decidedly different functions.

Plumwood held that if the relationship between the two is viewed as one between a culture and its physical environment, in that a culture can shape the way a physical environment is classified and indeed the physical features of it and vice versa, then each remains distinguishable aspects of the world so as to require considering and focusing on them separately. ${ }^{31}$ Though intertwined and interdependent, each is a separate and distinct phenomenon.

The sex versus gender distinction outlined above implicitly involves a dualism. Western culture has packed considerations of this dualist polarisation with implications of the female (nature, body and passivity) and the male (culture, reason and freedom) pointing to the male as separate and controlling.

30 Robert J. Stoller, Sex and Gender (New York: Science House, 1968), $15^{8}$.

31 Plumwood, ibid., 10. 
Western primary cultural thinking rests on this dualist thinking. With conception, for example, the sperm is commonly thought to compete to travel, surround and fight to win the right to implant the egg in the moment of conception. The average acculturated person would be surprised to know that the egg travels through the womb to the sperm, languishing for days waiting for the egg's arrival. The same holds for the egg emitting enzymes which either allow or disallow the penetration of the membrane by the sperm, effectively choosing which individual sperm will fertilise the egg. Dualist thinking has clearly shaped the very perception of conception.

Dualism, in this sense, amounts to denied dependency on a subordinated other; this determines a structure in which the denial and dominationsubordination relation shapes the identity of both. Simone de Beauvoir stated the dualism in this way:

The terms masculine and feminine are used symmetrically only as a matter of form, as on legal papers. In actuality, the relation of the two sexes is not quite like that of two electrical poles, for man represents both the positive and the neutral, as is indicated by the common use of man to designate human beings in general; whereas woman represents only the negative, defined by limiting criteria, without reciprocity. In the midst of an abstract discussion it is vexing to hear a man say: 'You think thus and so because you are a woman;' but I know that my only defence is to reply: 'I think thus and so because it is true,' thereby removing my subjective self from the argument. It would be out of the question to reply: 'And you think the contrary because you are a man', for it is understood that the fact of being a man is no peculiarity.

... [T] here is an absolute human type, the masculine. Woman has ovaries, a uterus; these peculiarities imprison her in her subjectivity, circumscribe her within the limits of her own nature. It is often said that she thinks with her glands. Man superbly ignores the fact that his anatomy also includes glands, such as the testicles, and that they secrete hormones. He thinks of his body as a direct and normal connection with the world, which he believes he apprehends objectively, whereas he regards the body of woman as a hindrance, a prison, weighed down by everything peculiar to it. ${ }^{32}$

From de Beauvoir's perspective, the very definition of woman and the bias that associates woman with characteristics considered negative allow and prepare 
for objectification and domination. In psychological language, the distinction between the class of females and the set of characteristics associated with them essentially explains why psychology has been called 'phallocentric' and has produced a false androcentrism.

False androcentrism, in this sense, has been described as an implicit 'natural' orientation towards an erroneous cultural ideal of a 'neutral' sex, one that holds itself as the standard against which to measure all humans, male and female. As this androcentric subject is implicitly male, the standard turns out to be phallocentric. Irigaray went so far as to state that Western culture in general is 'phallogocentric', ${ }^{33}$ suggesting that our cultural orientation is towards values and ideals governed by a social ideal of androcentrism. The application of the androcentric model to women, Irigaray held, objectifies, delimits, devalues and ignores the unique difference of perspective and experience that women bring to the world. ${ }^{34}$

Conversely, the sex-gender distinction has been critiqued as one that assumes the arbitrariness of the connection between the body and gender. ${ }^{35}$ This perspective assumes that gender, a matter of consciousness, is constructed on the body and that the body is passive and neutral regarding the formation of consciousness. Masculine and feminine behaviours are taken to be arbitrary, socially inscribed on an indifferent consciousness joined to an indifferent body. Hence, the sex-gender distinction implicitly involves a body-consciousness distinction of a rationalist or Cartesian type, with the body assumed neutral and passive. The consciousness assumed, however, remains neutral or implicitly male, whereas the object of discussion is the feminine equated with the body. This perspective removes the very possibility of speaking from a woman's unique subjectivity and promotes an objectification of the feminine. Irigaray commented on the objectification of the feminine:

Once imagine that woman imagines and the object loses its fixed, obsessional character. ... If there is no more 'earth' to press down/repress, to work, to represent, but also and always to desire (for one's own), no opaque matter which in theory does not know herself, then what pedestal remains for the ex-sistence of the 'subject'? If the earth turned and more especially turned upon herself, the erection of the subject might thereby be disconcerted and risk losing its elevation and penetration. For what would there be to rise up from and exercise his power over? And in? ${ }^{36}$

33 Luce Irigaray, Speculum of the Other Woman (New York: Cornell University Press, 1985).

34 Luce Irigaray, This Sex Which is Not One (New York: Cornell University Press, 1985).

35 JudithButler,BodiesThatMatter:OntheDiscursiveLimits of Sex(NewYork:Routledge, 1993).

36 Irigaray, This Sex Which is Not One, 1-219. 
Irigaray posited that the subject, always masculine, needs the objectification of the feminine and the body upon which to base his theories. In making the feminine into a property of his language, the masculine subject appropriates her, dominates her, and defines her according to his own needs and definitions, not to her own. As a cultural phenomenon, one could call this set of assumptions masculinism, one that assumes the subject as male or androcentric at best. This perspective excludes woman and the body, radically defined as other and ultimately dominated. Yet, the subject is always a sexed subject and the body is always a situated body, hence no neutral or passive body underlies gender.

Trying to treat gender as something inherently neutral is therefore mistaken, a mistake situated in the radical separation of particular gender characteristics, as well as the removal of the body from consideration. In this sense, the body has been objectified, transformed into that which must be dominated, controlled, manipulated and ordered.

As Elwin Susan John has posited, '... the human body is a space and a canvass for the expression of human sufferings, ${ }^{37}$ highlighting the idea that the body has been formulated to carry cultural inscriptions. As receivers and participants of this cultural baggage, women with eating disorders can be seen as internalising and perpetuating this self-objectification. This self-objectification can be viewed as actual struggle for definition:

The struggle for definition is veritably the struggle for life itself. In the typical Western, two men fight for the possession of a gun that has been thrown to the ground; whoever reaches the weapon first, shoots and lives; his adversary is shot and dies. In ordinary life, the struggle is not for guns but for words; whoever first defines the situation is the victor; his adversary, the victim. For example, in the family, husband and wife, mother and child do not get along; who first defines whom as troublesome or mentally sick? Or in the apocryphal story about Emerson visiting Thoreau in jail; Emerson asks : 'Henry, what are you doing over there?' Thoreau replies: 'Ralph, what are you doing over there?' In short, he who first seizes the word thus dominates and lives; and he who is defined is subjugated and may be killed. ${ }^{38}$

In this view, the development of a clinical eating disorder can be seen as an attempt to define self in response to a cultural definition and subsequent

\footnotetext{
37 Elwin, Susan John, 'I Used To Be Human Once: Trauma and Reconfigurations of the Body in Chemical Disasters', in this volume. 
domination of the woman's self-perception. The eating disordered woman seeks to define herself first, by controlling her eating and therefore her body, consciously or unconsciously. Elwin Susan John calls this phenomenon '... the 'body' holds a unique status of being what is affected and also being a tool for protest.' ${ }^{39}$

As clinical eating disorders have gained cultural validity and general recognition since Karen Carpenter's death, many empirical studies have been performed that directly and causally link the clinical eating disorder phenomenon with various gender role aspects. ${ }^{40}$ Some studies held that eating disorders may be affiliated, but are not directly connected to a more traditional gender role identity ${ }^{41}$ Other alternate studies posited an actual direct connection between the preponderance of femininity and clinically disordered eating patterns. ${ }^{42}$ After review, vast disagreements exist in the clinical eating disorder literature regarding the phenomenon of gender roles. ${ }^{43}$

What is even more unclear is the intertwining meaning of gender and embodiment in those women with clinically diagnosed eating disorders. Butler pulled apart the classic sex versus gender distinction as a meaningless question, not relevant for examination, as she held that gender and the body already circumscribe existence. ${ }^{44}$ Within this framework, the analysis of distinct characteristics such as gender role is irrelevant. ${ }^{45}$ Separation of a particular characteristic to examine in detail is impossible, as each quality is inextricably informed by other qualities.

Honouring this inextricability, Bordo directly connected the theoretical consideration of clinical eating disorders with gender and the body in her analysis of the psychopathology of anorexia as the very crystallisation or embodiment of culture. This conceptualisation of clinical eating disorders is the most encompassing of the theoretical constructs in the current clinical and

39 Elwin Susan John, ibid.

40 Mark E. Johnson, Christiane Brems and Pamela Fischer, 'Sex Role Conflict, Social Desirability, and Eating-Disorder Attitudes and Behaviors', Journal of General Psychology 123.1 (1996): 75-87.

41 Ellen C. Flannery-Schroeder and Joan C. Chrisler, 'Body Esteem, Eating Attitudes, and Gender-Role Orientation in Three Age Groups of Children', Current Psychology: Developmental, Learning, Personality, Social 15.3 (1996): 235-248.

42 Snyder and Hasbrouck, 'Feminist Identity, Gender Traits, and Symptoms of Disturbed Eating among College Women', Psychology of Women Quarterly, 20.4, 593-598.

43 Helen Malson, 'Women under Erasure: Anorectic Bodies in Postmodern Context', Journal of Community and Applied Social Psychology 9.2 (1999): 137-153.

44 Butler, Bodies that Matter, 1-256.

45 Judith Butler, GenderTrouble:Feminismand the Subversion of Identity (New York:Routledge, 1990), 1-272. 
theoretical literature. Bordo held that the phenomenon of clinical eating disorders is synchronous with three cultural axes, which therefore encompass the clinical eating-disordered persons' worldview: the dualist axis, the control axis and the gender-power axis. ${ }^{46}$

The dualist axis is characterised by the view that human existence is bifurcated into two territories or substances: that of the body and materiality, and alternatively, that of the mental and spiritual. The thinking of our cultural philosophical ancestors, such as Plato, Augustine and Descartes, fully promoted, and in fact, demanded the dualist perspective as priority. For each of these philosophers, the body was considered alien, something to escape from, a confinement or an enemy, and that which threatens and thwarts our every attempt at control. Far from philosophical, however, those with eating disorders similarly embrace this perspective concerning their very own bodies. For these people, the body is something from which they must escape - a prison or an enemy against which to struggle. The body is not seen as self, but as other, that which must be conquered and dominated. In this battle, thinness represents an eventual desired triumph of the spirit or the will over the body, an essentially dualist stance.

The control axis is informed by this person's experience of her body, life and hungers as being out of control. The bulimic may shamefully feel that once she starts eating, she cannot control herself, and may also actively dissociate during eating. The anorectic is usually a perfectionist, wanting to shine in all aspects of her life. The anorectic syndrome may occur as a result of her initiating a diet rather casually, after which she becomes hooked on the intoxicating feelings of control and accomplishment - often the only control she may experience in her life.

The gender-power axis reflects the fact that women, by far, are more obsessed and less satisfied with their bodies than men and are permitted less physical latitude with their bodies by themselves, men and culture. ${ }^{47}$ Current statistics claim that four out of five women feel dissatisfied with their appearance. The average American woman is five feet four inches tall and weighs 140 pounds, whereas fashion models are on average five feet eleven inches tall and 117 pounds, making models thinner than 98 percent of women. ${ }^{48}$ This comparison worsens after the manipulation of models' pictures, often showing body proportions of an impossible ratio. Many clinical eating-disordered persons experience

46 Bordo, Unbearable Weight, 1-44.

47 Ibid., 1-44.

48 Smolak, Levine and Striegel-Moore, The Developmental Psychopathology of Eating Disorders, 1-464. 
the female portions of their bodies as a disgusting appropriation of their body by fat. They experience amenorrhea as a profound relief from the burden of menstruation and procreation. These symptoms can be seen as conscious or unconscious feminist protest at the restricting limitations of the traditional female role, representing a striving for a cultural shift in gender role considerations.

\section{$5 \quad$ Treatment Implications}

Successful interventions with clinical eating disorders take the multiplicity of intersecting factors discussed above into account. Clinical eating disorders are most often successfully treated when diagnosed very early, before the problematic behaviours solidify and become inextricably entrenched in the anorectic's psyche and routine behaviour patterns. The anorectic's very sense of self crystallise to encompass restricting eating and excessive exercise, so an earlier intervention can lead to more favourable outcomes. Unfortunately, due to the social approval that girls with bodies that conform towards a feminine ideal, individuals with clinical eating disorders may often deny their problem for years and thus may not receive necessary medical or psychological attention until they have already become seriously entrenched in their behaviour patterns and are dangerously thin and malnourished. ${ }^{49}$ People with bulimia are often normal weight and may unfortunately often be able to hide their illness from family members, friends, and medical personnel for years. Clinical eating disorders in males may be overlooked because they have been historically rare in boys and men. ${ }^{50}$

Consequently, getting - and keeping - people with these disorders into early treatment, while essential, can be extremely challenging and difficult to accomplish. The longer abnormal eating behaviours persist, the more the behaviours become deep-seated and it is increasingly difficult to overcome the disorder and its negative effects on the body, which may, over time, become permanent. In some cases, long-term wrap-around medical hospitalisation treatment may be required, in order to entirely disrupt the negative behaviour pattern. Families and friends offering support and encouragement can play an essential, critical, and important role in the success of the treatment program, and aftercare regimen. ${ }^{51}$

49 Ibid, 1-464.

50 American Psychiatric Association, Diagnostic and Statistical Manual of Mental Disorders.

$5^{1} \quad$ Snyder and Hasbrouck, 'Feminist Identity, Gender Traits, and Symptoms of Disturbed Eating among College Women', Psychology of Women Quarterly, 20.4, 593-598. 
Once a clinical eating disorder is diagnosed, the clinician must determine whether the patient is in immediate medical danger and requires hospitalisation. Although some patients can be successfully treated as outpatients, many more need extensive hospital care, given the extreme risks associated with clinical eating disorders. Conditions that may warrant hospitalisation include excessive and rapid weight loss, serious metabolic or endocrine disturbances, clinical depression or risk of suicide, risk of heart attack or stroke, severe binge eating and purging, and psychosis.

The complex interaction of cultural, emotional, psychological and physiological problems in clinical eating disorders calls for a comprehensive physical examination and treatment plan involving, ideally, an internist, a nutritionist, a psychologist and a prescriber. The use of long-term individual psychotherapy, family therapy and cognitive-behavioural therapy contribute to the common successful long-term interventions. Group therapy, in which patients share their experiences with other patients with similar problems, proves especially effective for individuals with bulimia. ${ }^{52}$ The patients benefit through sharing their experiences with like-minded others who do not judge them, often the first time the patient may have experienced such unbiased witnessing. Cognitive-behaviour therapists focus on changing eating behaviours usually by rewarding and/or modelling wanted behaviour, in order to interrupt problematic eating behaviour and shape healthier eating behaviour. Token economies are one example of this strategy. Family-focused therapists intervene with patients and their family systems to change problematic dynamics into more healthful support for the patient. Key in any therapeutic approach is to help patients work to change the distorted and rigid thinking patterns associated with clinical eating disorders, as well as to change the actual disordered eating patterns.

Some form of extensive longer-term psychotherapy is usually necessary to help those with clinical eating disorders deal with their illnesses and possible concomitant underlying emotional issues. The psychotherapy should be provided by an appropriately credentialed mental health professional who meets with the patient individually to provide extended and ongoing emotional support while the patient begins and continues to understand and cope with the illness. Behaviour change should be expected to be an extremely slow process and contiguous long-term care for family members is also highly recommended.

Scientists supported by the National Institute for Mental Health have examined the effectiveness of combining psychotherapy and medications. 
Researchers found that both intensive group therapy and antidepressant medications, combined or alone, benefited patients. ${ }^{53}$ In another study of bulimia, the combined use of cognitive-behavioural therapy and antidepressant medications was most beneficial. ${ }^{54}$ The combination treatment was particularly effective in preventing relapse once medications were discontinued. For patients with binge-eating disorder, cognitive-behavioural therapy and antidepressant medications may also prove useful. ${ }^{55}$ Antidepressant medications commonly used to treat bulimia include desipramine, imipramine and fluoxetine. For anorexia, some antidepressant medications may be effective when combined with other forms of treatment. Fluoxetine has also been useful in treating some patients with binge-eating disorder. These antidepressants may also treat any co-occurring depression. ${ }^{56}$

The efforts of mental health professionals need to be combined with those of other health care professionals in order to obtain the most effective treatments for persons with clinical eating disorders. In addition to psychotherapists, physicians may treat any medical complications the patient experiences and nutritionists may advise the patient on diet and eating regimens. The challenge of treating clinical eating disorders increases with the metabolic changes associated with them. Just to maintain a stable weight, individuals with anorexia may actually have to consume more calories than would individuals without an eating disorder of similar weight and age. This information is important for the patients and the clinicians who treat them. Consuming calories is exactly what the person with anorexia wishes to avoid, yet must do to regain the weight necessary for recovery. In contrast, some normal-weight people with bulimia may gain excess weight if they consume the number of calories required to maintain normal weight in others of similar size and age.

\section{Conclusion}

A thorough understanding of the relevant cultural history, triggers, traumatic context, and evidence-based effective treatments for anorexia must be assessed in order to effectively treat an anorexic patient. It will be essential to address the prevalent negative cultural perceptions of bodies in order to increase women's

\footnotetext{
53 Ibid., 4-16.

54 Ibid., 4-16.

55 American Psychiatric Association, Diagnostic and Statistical Manual of Mental Disorders.

56 Ibid.
} 
self-esteem. The increase in self-esteem and the decrease of negative perceptions of their own bodies will in turn assist the woman to change her internalised dialogue regarding her body, and change previously pejorative evaluations to more positive self-talk. It will be essential that the future efforts of mental health professionals will need to be combined with those of other health professionals to obtain the best wrap-around treatment for those with clinical eating disorders.

\section{Bibliography}

American Psychiatric Association. Diagnostic and Statistical Manual of Mental Disorders, 5 th ed. Washington, DC: American Psychiatric Association, 2013.

Bordo, Susan. Unbearable Weight. Berkeley, CA: University of California Press, 1993.

Breuer, Joseph, and Sigmund Freud. Studies on Hysteria. New York: Penguin Press, 1982.

Bruch, Hilde. Eating Disorders: Obesity, Anorexia Nervosa, and the Person Within. New York: Basic Books, 1973.

Bruch, Hilde. The Golden Cage: The Enigma of Anorexia Nervosa. New York: Vintage, 1979.

Butler, Judith. Bodies that Matter: On the Discursive Limits of Sex. New York: Routledge, 1993 .

Butler, Judith. Gender Trouble: Feminism and the Subversion of Identity. New York: Routledge, 1990.

Crowther, Janis H., Eve M. Wolf, and Nancy E. Sherwood. 'Epidemiology of Bulimia Nervosa.' The Etiology of Bulimia Nervosa: The Individual and Familial Context, edited by Janis H. Crowther and Daniel L. Tenenbaum, 4-16. Washington, DC: Hemisphere Publishing Corporation, 1992.

Eschholz, Rosa P., and V. Clark. Language Awareness. London: St. Martin's Press, 1986.

de Beauvoir, Simone. The Second Sex. New York: Vintage, 1974.

Faludi, Susan. Backlash: The Undeclared War against American Women. New York: Doubleday, 1991.

Flannery-Schroeder, Ellen C., and Joan C. Chrisler. 'Body Esteem, Eating Attitudes, and Gender-Role Orientation in Three Age Groups of Children.' Current Psychology: Developmental, Learning, Personality, Social 15.3 (1996): 235-248.

Foucault, Michel. Discipline and Punish: The Birth of the Prison. New York: Vintage/Random House, 1979 .

Gergen, Mary and Sara Davis. Towards a New Psychology of Gender. New York: Routledge, 1997 .

Irigaray, Luce. Speculum of the Other Woman. New York: Cornell University Press, 1985. Irigaray, Luce. This Sex Which Is Not One. New York: Cornell University Press, 1985. 
Johnson, Mark E., Christiane Brems, and Pamela Fischer. 'Sex Role Conflict, Social Desirability, and Eating-Disorder Attitudes and Behaviors.' Journal of General Psychology 123.1 (1996): 75-87.

Lefkowitz, Mary R. and Maureen B. Fant. Women's Life in Greece and Rome. Baltimore: Johns Hopkins University Press, 1982.

Malson, Helen. 'Women under Erasure: Anorectic Bodies in Postmodern Context.' Journal of Community and Applied Social Psychology 9.2 (1999): 137-153.

Micale, Mark S. 'Hysteria and Historiography: A Review of Past and Present Writings.' History of Science 27.78 (1989): 319-351.

Perlick, Deborah, and Brett Silverstein. 'Faces of Female Discontent: Depression, Disordered Eating, and Changing Gender Roles.' Feminist Perspectives on Eating Disorders, edited by Patricia Fallon, Melanie A. Katzman and Susan C. Wooley, 77-93. New York: Guilford Press, 1994.

Plumwood, Val. 'Do We Need a Sex Gender Distinction?' Radical Philosophy 51 (1989): 2-11. Samberg, Joel. 'Remembering Karen Carpenter, 30 Years Later.' NPR Music (website), 4 February 2013. Viewed on 9 April 2015. http://www.npr.org/2013/o2/04/171080334/ remembering-karen-carpenter-3o-years-later.

Savage, George H. Insanity and Allied Neurosis. Philadelphia: Henry C. Lea, 1884.

Smolak, Linda, Michael P. Levine, and Ruth Striegel-Moore. The Developmental Psychopathology of Eating Disorders: Implications for Research, Prevention, and Treatment. Mahway, NJ: Lawrence Erlbaum Associates, 1996.

Snyder, Rita, and Lynn Hasbrouck. 'Feminist Identity, Gender Traits, and Symptoms of Disturbed Eating among College Women.' Psychology of Women Quarterly 20.4 (1996): 593-598.

Stoller, Robert J. Sex and Gender. New York: Science House, 1968. 